\title{
EVALUATION OF THERMAL STRESSED STATE IN WELDED JOINT OF ALLOY Inconel 690
}

\author{
N.O. CHERVYAKOV \\ E.O. Paton Electric Welding Institute, NASU \\ 11 Bozhenko Str., 03680, Kiev, Ukraine. E-mail: office@paton.kiev.ua
}

\begin{abstract}
The results of evaluation of thermal stressed state in welded joint of nickel alloy Inconel 690 are presented. The experimental-calculation analysis of thermal processes and mathematical modeling of stress-strain state in single-pass welding was performed. The verification of the data by comparing the experimental thermal cycles with the calculated ones showed a good similarity of results of both as to the sizes of a weld as well as to the thermal cycles in the zones at the different distance from the fusion line. The kinetics of stress-strain state in different zones of welded joint was analyzed considering the probability of hot crack formation. It is shown that under the conditions of modeling linear one-pass welding of plates of $3 \mathrm{~mm}$ thickness with energy input of $304 \mathrm{~J} / \mathrm{mm}$ the arising stresses and deformations do not exceed the critical values and, at the same time do not create the conditions for hot crack formation. The applied mathematical model can be used in evaluation of kinetics of stress-strain state for different variants of welding (change in energy input, different filler material, etc.). 7 Ref., 1 Table, 5 Figures.
\end{abstract}

Keywords: nonconsumable-electrode arc welding, nickel alloys, thermal processes, thermal cycles, mathematical modeling, stresses, deformations

The nickel-based alloys play an important role as corrosion-resistant materials in the nuclear and chemical industries, especially under conditions of operation at the high temperatures, considerable stresses and aggressive environments. The widely used nickel-based alloys at the present time are alloys of $\mathrm{Ni}-\mathrm{Cr}-\mathrm{Fe}$ alloying system. One of such alloys is Inconel 690 with high chromium content $(30 \%)$ [1]. The welded joints of Inconel 690 with appropriate filler materials showed a high sensitivity to hot crack formation, particularly under the conditions of welding of thick-walled structural elements. The alloys manifest the highest tendency to the formation of ductility-dip cracks [2, 3].

As was shown previously [4], the ductility-dip cracks in welding of alloys of alloying system $\mathrm{Ni}-\mathrm{Cr}-\mathrm{Fe}$ occur at the temperature range of $1050-650{ }^{\circ} \mathrm{C}$, the value of critical deformation of crack formation $\varepsilon_{\text {cr }}$ is about $1.2 \%$.

The thermal processes in fusion welding have a decisive influence on the nature and kinetics of changes in the stress-strain state, structure and properties of weld and HAZ. In this regard, the analysis of temperature fields in welding of alloys of $\mathrm{Ni}-\mathrm{Cr}-\mathrm{Fe}$ alloying system with the aim of further investigations of kinetics of stress-strain state and evaluation of tendency to hot crack formation is an urgent problem.

The aim of the work was a comparative experimental and calculation analysis of tempera-

(C) N.O. CHERVYAKOV, 2015 ture fields and modeling of stress-strain state in one-pass argon-arc welding of alloy Inconel 690.

The computer prediction and calculation allow determining the temperature fields for different values of thermal power of the arc. Using the calculation procedure the efficiency coefficient of the arc is established, which varies depending on the method and conditions of welding, etc. To specify the input data of mathematical model the experimental plotting of thermal cycles and their comparison with the calculated values is required.

The recording of welding thermal cycles was carried out on the Inconel 690 specimens of $170 \times$ $\times 40 \times 3 \mathrm{~mm}$ size. TIG welding in argon without fillers was carried out at the following conditions: $I_{\mathrm{w}}=72 \mathrm{~A}, U_{\mathrm{w}}=10.5 \mathrm{~V}, v_{\mathrm{w}}=7.2 \mathrm{~m} / \mathrm{h}$. The gas consumption in welding amounted to $5 \mathrm{l} / \mathrm{min}$.

For measurements of thermal cycles of welding in the HAZ the thermocouples of type $\mathrm{K}$ (chromel-alumel) were used. The diameter of thermoelectrodes was $0.2 \mathrm{~mm}$, the diameter of hot junction was smaller than $0.5 \mathrm{~mm}$. The junction of thermocouple was produced by fusion of thermoelectrodes using manual argon arc welding. The calibration of thermocouples was carried out according to the melting temperatures of commercially pure aluminum and copper.

The record of thermal cycles was carried out in real time using ADC Expert 9018R and specialized software PowerGraph 3.0 allwoing the automatic convertion of the values of thermal EMF to the temperature.

To the surface of plates the junctions of thermocouples were fixed by capacitor-type welding, that ensured a permanent stable contact of the 


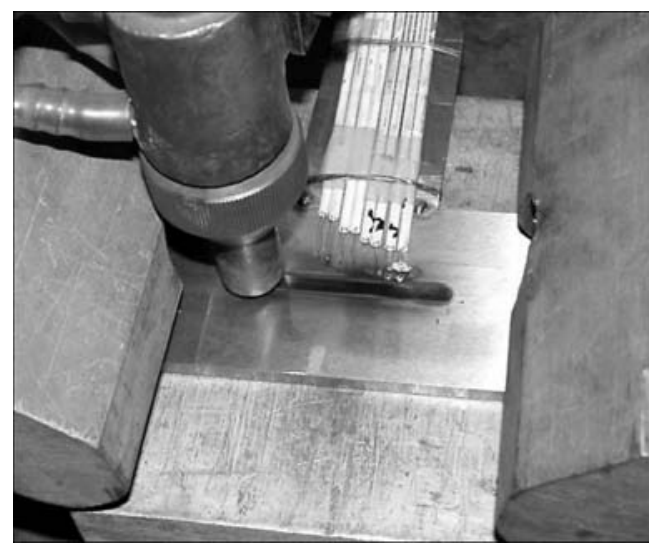

Figure 1. General view of specimen with weld and thermocouples after welding

junction with the metal in a wide temperature range. The appearance of the specimen with welded-in thermocouples after welding is shown in Figure 1.

After welding the weld and thermocouples in the HAZ were photographed in binocular microscope with 25-fold magnification and the measurement of distances from the fusion line to the thermocouple junctions was carried out. In addition, on the macrosections the weld width and penetration depth were measured.

The calculated evaluation of thermal stressed state was performed using the specialized software «Welding of nickel alloys», created on the basis of algorithms developed at the E.O. Paton Electric Welding Institute, and describing the distribution of temperatures and stress-strain state near the weld pool of complex-alloyed alloys based on nickel. For the considered plate, in the process of welding heating the temperature field $T(x, y, z, t)$ in time was determined. Then, according to the average values of temperature $T(x, y, t)$ the problem of kinetics of the stresses and deformations was solved [5, 6]. It was based on the method of successive tracking in time with

\section{$y, \mathrm{~mm}$}

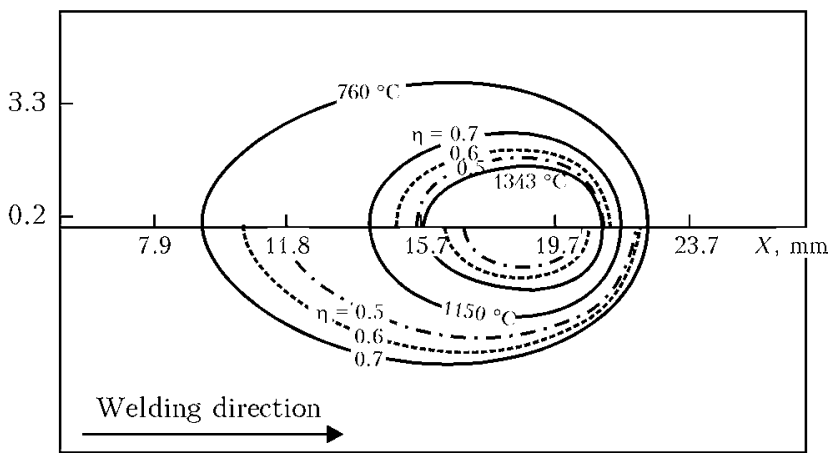

Figure 2. Influence of values of arc efficiency factor $\eta$ on temperature distribution in the high-temperature region

pitch $\Delta t$ and the finite element method in space, i.e. the considered area was represented by a totality of elementary volumes of $h_{x} \times h_{y} \times h_{z}$ sizes. The size of a single element in the model amounts to $0.5 \times 0.5 \times 0.5 \mathrm{~mm}$.

For evaluation of the regularities of temperature distribution in the weld and HAZ joints using calculation method the temperature dependencies of change in heat capacity and thermal conductivity of the investigated material were used. These values for alloy Inconel 690 were chosen according to the data of literature sources, and also considering the own investigations $[1,7]$.

The arc efficiency factor $\eta$, used in the calculations, for TIG process amounts to $0.50-0.75$. The temperature fields at the values of this factor of $0.5,0.6$ and 0.7 were calculated. Figure 2 shows that there is a significant influence of arc efficiency factor both on the heat distribution, as well on the shapes of isotherms. In modeling $\eta=0.70-0.75$ was selected, as far as the appropriate temperature field correlates well with the experimental results.

The first stage of modeling was the determination of temperature fields, taking into account

Temperature dependence of thermophysical properties of alloy Inconel 690

\begin{tabular}{|c|c|c|c|c|c||}
\hline Temperature, ${ }^{\circ} \mathrm{C}$ & Young's modulus, $\mathrm{MPa}$ & Yield strength, MPa & $\begin{array}{c}\text { Coefficient of thermal } \\
\text { expansion, } / \text { deg }\end{array}$ & $\begin{array}{c}\text { Thermal conductivity, } \\
\text { W/(cm.deg) }\end{array}$ & $\begin{array}{c}\text { Heat capacity, } \\
\mathrm{J} /(\mathrm{g} \cdot \mathrm{deg})\end{array}$ \\
\hline 20 & 205,000 & 348 & 0.00001406 & 0.115 & 0.453 \\
\hline 100 & 204,000 & 281 & 0.00001406 & 0.130 & 0.474 \\
\hline 200 & 193,000 & 248 & 0.00001431 & 0.155 & 0.496 \\
\hline 300 & 187,000 & 240 & 0.00001453 & 0.173 & 0.523 \\
\hline 400 & 185,000 & 231 & 0.00001480 & 0.190 & 0.557 \\
\hline 500 & 177,000 & 225 & 0.00001519 & 0.212 & 0.574 \\
\hline 600 & 167,000 & 215 & 0.00001570 & 0.227 & 0.608 \\
\hline 700 & 158,000 & 200 & 0.00001618 & 0.250 & 0.633 \\
\hline 800 & 152,000 & 190 & 0.00001660 & 0.269 & 0.660 \\
\hline 900 & 145,000 & 175 & 0.00001701 & 0.285 & 0.690 \\
\hline 1000 & 135,000 & 150 & 0.00001741 & 0.303 & 0.715 \\
\hline 1100 & 125,000 & 125 & 0.00001779 & 0.318 & 0.739 \\
\hline 1200 & 100,000 & 100 & 0.00001800 & 0.332 & 0.769 \\
\hline
\end{tabular}





Figure 3. Distribution of temperature fields in the plane $X Y$ and across the plate thickness

the temperature-dependent properties of material (specific heat, thermal conductivity) and temperature losses as a result of convection and radiation.

The temperatures of melting and solidification were taken as 1377 and $1343{ }^{\circ} \mathrm{C}$, respectively [1].

Figure 3 shows the results of calculation of temperature distribution along the surface of source movement at the steady state in the area of weld pool and HAZ. Due to symmetry of the solved problem a half of the plate is shown in this Figure.

The verification of the calculated temperature fields with the thermal cycles and actual sizes of the weld, measured using thermocouples, were carried out. The comparison of the data showed a good similarity of results both as to the sizes of weld (weld width and penetration depth in the experiment were 4.2 and $1.3 \mathrm{~mm}$, respectively, in modeling they were 4.1 and $1.4 \mathrm{~mm}$ ) as well as to the thermal cycles at the points at different distances from the fusion line. Thus, the validity of using the initial thermophysicalcharacteristics for calculation of temperature distribution in welded joint in welding of alloys of $\mathrm{Ni}-\mathrm{Cr}-\mathrm{Fe}$ alloying system was confirmed.

The modeling of stress-strain state was performed taking into account the temperature dependence of physical and mechanical properties of the alloy, including modulus of elasticity, yield strength and coefficient of thermal expansion. All these characteristics were determined experimentally within the temperature range of up to $1100{ }^{\circ} \mathrm{C}$. The yield strength and modulus of elasticity were determined in installation MTS-810, the evaluation of linear expansion coefficient was performed in the contact-free laser dilatometer. The data on thermal and mechanical properties are presented in the Table.

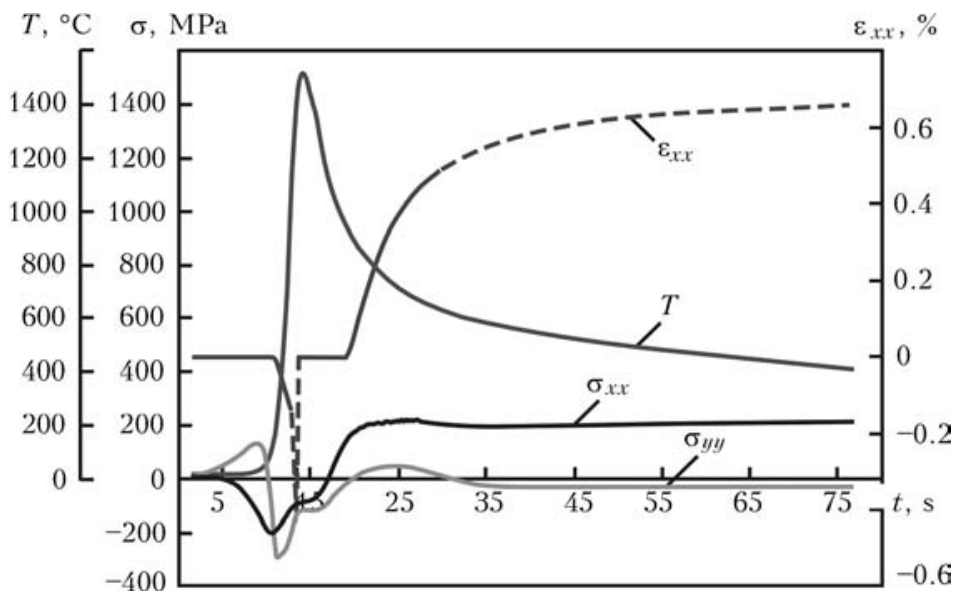

Figure 4. Kinetics of change in temperature $T$, longitudinal $\sigma_{x x}$ and transverse $\sigma_{y y}$ stresses and longitudinal plastic deformations $\varepsilon_{x x}$ along the weld axis during welding 


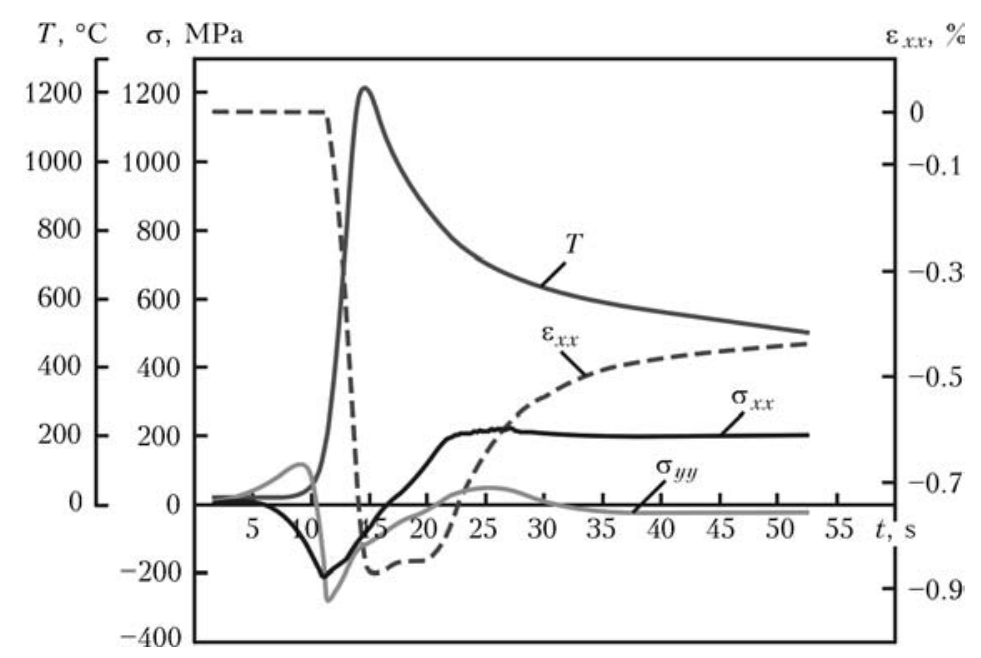

Figure 5. Kinetics of change in temperature $T$, longitudinal $\sigma_{x x}$ and transverse $\sigma_{y y}$ stresses and longitudinal plastic deformations $\varepsilon_{x x}$ in HAZ at $0.5 \mathrm{~mm}$ distance from the fusion line during welding

Taking into account the calculated temperature fields the modeling of stress-strain state during welding was performed. The distributions of temporary and residual stresses and deformations for different zones of welded joint were obtained.

The investigations of weldability of alloys of $\mathrm{Ni}-\mathrm{Cr}-\mathrm{Fe}$ alloying system showed [4] that the crack formation in the weld and HAZ is possible at distance of $0.5-3.0 \mathrm{~mm}$ from the fusion line. In this regard, the kinetics of thermal stressed state was considered in the weld and HAZ at distance of $0.5 \mathrm{~mm}$ from the fusion line (Figures 4 and 5).

At the beginning of heating cycle, the metal is subjected to compressive longitudinal $\sigma_{x x}$ and transverse $\sigma_{y y}$ stresses. The longitudinal plastic deformations $\varepsilon_{x x}$ are also compressive, their value reaches $0.9 \%$. At the subsequent cooling, the tensile stresses of both longitudinal and transverse nature occur. The longitudinal stresses reach $215 \mathrm{MPa}$ and are significantly larger than the transverse ones, which are equal to $40 \mathrm{MPa}$. The longitudinal stresses reach maximum values during cooling to $650{ }^{\circ} \mathrm{C}$. With the further cooling, the longitudinal stresses remain at a constant level, and the transverse ones are gradually decreasing. The longitudinal plastic deformations during cooling have positive increments to $0.5 \%$.

Basing on these results it can be concluded that for the given conditions of modeling of single-pass welding, the maximum increments of plastic deformation coincide with the temperature range of brittleness of the alloy and are propagated simultaneously with increase in the longitudinal tensile stresses, but they are not sufficient for the ductility-dip crack formation.

\section{Conclusions}

1. Using experimental and calculation procedure the evaluation of temperature fields in single-pass welding of nickel alloy Inconel 690 was carried out. The comparison of the data showed a good similarity of results of both as to the sizes of the weld and also as to the thermal cycles at the points at different distance from the fusion line, that confirms the validity of using the initial thermophysical characteristics of metal for calculation of temperature distribution in the welded joint.

2. Taking into account the experimentally determined physical and mechanical properties of the alloy, the mathematical modeling of stressstrain state was performed and the kinetics of changes in stresses and deformations was considered for different zones of welded joint. It is shown that under the conditions of modeling of linear single-pass welding of plates of $3 \mathrm{~mm}$ thickness at energy input of $304 \mathrm{~J} / \mathrm{mm}$ the occuring stresses and deformations do not exceed the critical values, and the conditions for hot crack formation are not created.

1. (2009) Inconel ${ }^{\circledast}$ alloy 690 . URL: $h t t p: / /$ www.specialmetals.com/documents / Inconel\%20alloy\%20690. pdf

2. Kiser, S.D., Zhang, R., Baker, B.A. (2009) A new welding material for improved resistance to ductility dip cracking. In: Proc. of 8th Int. Conf. on Trends in Welding Research (Pine-Mountain, GA, 2009), 639-644.

3. Nishimoto, K. (2006) Microcracking in multipass weld metal of alloy 690. Pt 1: Microcracking susceptibility in reheat weld metal. Sci. and Techn. of Welding and Joining, 11(4), 455-461.

4. Yushchenko, K.A., Savchenko, V.S., Chervyakov, N.O. (2011) Comparative evaluation of sensitivity of welded joints on alloy Inconel 690 to hot cracking. The Paton Welding J., 11, 2-7.

5. Makhnenko, V.I. (1976) Computational methods for investigation of kinetics of welding stresses and strains. Kiev: Naukova Dumka.

6. Yushchenko, K.A., Makhnenko, V.I., Savchenko, V.S. et al. (2007) Investigation of thermal-deformation state of welded joints in stable-austenitic steels and nickel alloys. Welding in the World, 51(9/10), 51-55.

7. Yushchenko, K.A., Savchenko, V.S., Zvyagintseva A.V. et al. (2014) Physical-mechanical characteristics of In690 type weld in high-temperature range of ductility deep. In: Proc. of 55th Int. Conf. on Actual Problems of Strength (Kharkov, Ukraine, 2014), 189.

Received 28.09.2015 